\title{
Local velocity scaling in T400 vessel agitated by Rushton turbine in a fully turbulent region
}

\author{
Radek Šulc ${ }^{1,{ }^{*}}$, Pavel Ditl ${ }^{1}$, Ivan Fořt ${ }^{1}$, Darina Jašíkova ${ }^{2}$, Michal Kotek $^{2}$, Václav Kopecký², and Bohuš Kysela ${ }^{3}$ \\ ${ }^{1}$ Czech Technical University in Prague, Faculty of Mechanical Engineering, Department of Process Engineering, Technická 4, 16607 \\ Prague, Czech Republic \\ ${ }^{2}$ Technical University of Liberec, Institute for Nanomaterials, Advanced Technology and Innovation, Studentská 1402/2, 461 17 Liberec, \\ Czech Republic \\ ${ }^{3}$ Czech Academy of Sciences, Institute of Hydrodynamics v.v.i, Pod Pat'ankou 30/5, 16612 Prague, Czech Republic
}

\begin{abstract}
The hydrodynamics and flow field were measured in an agitated vessel using 2-D Time Resolved Particle Image Velocimetry (2-D TR PIV). The experiments were carried out in a fully baffled cylindrical flat bottom vessel $400 \mathrm{~mm}$ in inner diameter agitated by a Rushton turbine $133 \mathrm{~mm}$ in diameter. The velocity fields were measured in the zone in upward flow to the impeller for impeller rotation speeds from $300 \mathrm{rpm}$ to $850 \mathrm{rpm}$ and three liquids of different viscosities (i.e. (i) distilled water, ii) a $28 \%$ vol. aqueous solution of glycol, and iii) a $43 \%$ vol. aqueous solution of glycol), corresponding to the impeller Reynolds number in the range $50000<\operatorname{Re}<189000$. This Re range secures the fully-developed turbulent flow of agitated liquid. In accordance with the theory of mixing, the dimensionless mean and fluctuation velocities in the measured directions were found to be constant and independent of the impeller Reynolds number. On the basis of the test results the spatial distributions of dimensionless velocities were calculated. The axial turbulence intensity was found to be in the majority in the range from 0.388 to 0.540 , which corresponds to the high level of turbulence intensity.
\end{abstract}

\section{Introduction}

It is important to know the flow and the flow pattern in an agitated vessel in order to determine many impeller and turbulence characteristics, e.g. impeller pumping capacity, intensity of turbulence, turbulent kinetic energy, convective velocity, and the turbulent energy dissipation rate. The information and data that are obtained can also be used for CFD verification.

In PIV studies, the spatial distributions of various properties are often presented. However, the inspection analysis shows that the validity of the spatial distribution of any dimensionless property for arbitrary process conditions in geometrically similar agitated vessels requires independence of a given dimensionless property from the impeller Reynolds number. The spatial distribution that is obtained is in general valid only when this independence is both theoretically predicted and experimentally verified. Unfortunately, in many studies the results are presented only for one impeller speed and, in addition, when a Rushton turbine is used as an impeller, the experiments are often carried out in the transient flow regime.

Secondly, the flow discharging from an impeller has been investigated mainly, while the regions outside the impeller region have not been treated with the same level of interest ([1]). In our previous work [2] the local velocity profiles in the zone in upward flow to the impeller for three impeller rotation speeds in a vessel $300 \mathrm{~mm}$ in the inner diameter filled by a water and agitated by a Rushton turbine were presented.

The aim of this work is to study scaling of the velocity field outside the impeller region in a vessel 400 $\mathrm{mm}$ in inner diameter mechanically agitated by a Rushton turbine in a fully turbulent region for three liquids of different viscosities. The independency of dimensionless spatial velocity distribution on the impeller Reynolds number was tested statistically. The hydrodynamics and the flow field were measured in an agitated vessel using Time Resolved Particle Image Velocimetry (TR PIV).

\section{Theoretical background}

\subsection{Inspection analysis of flow in an agitated vessel}

The flow of a Newtonian fluid in an agitated vessel has been described by the Navier - Stokes equation:

$\rho \cdot\left(\frac{\partial \vec{U}}{\partial t}+\vec{U} \bullet \nabla \vec{U}\right)=-\nabla p+\mu \cdot \nabla^{2} \vec{U}+\rho \cdot \vec{g}$

\footnotetext{
Corresponding author: radek.sulc@fs.cvut.cz
} 
This equation can be rewritten into dimensionless form, as follows (e.g. [3]):

$$
\left(\frac{\partial \vec{U}^{*}}{\partial t^{*}}+\vec{U}^{*} \bullet \nabla^{*} \vec{U}^{*}\right)=-\nabla^{*} p^{*}+\frac{1}{\operatorname{Re}} \cdot \nabla^{* 2} \vec{U}^{*}+\frac{1}{F r} \cdot \vec{n}^{*}
$$

where the dimensionless properties are defined as follows:

- dimensionless instantaneous velocity:

$$
\vec{U}^{*}=\frac{\vec{U}}{N \cdot D}
$$

- dimensionless instantaneous pressure:

$$
p^{*}=\frac{p}{\rho \cdot N^{2} \cdot D^{2}}
$$

- dimensionless space gradient: $\nabla^{*}=\frac{\nabla}{D}$,

- impeller Reynolds number $\operatorname{Re}=\frac{N \cdot D^{2}}{v}$

- impeller Froude number: $\quad F r=\frac{N^{2} \cdot D}{g}$,

and where $\vec{n}$ is a unity vector.

Similarly, the equation of continuity for stationary flow of a non-compressible fluid is given

$$
\nabla \bullet \vec{U}=0
$$

and one can be rewritten into the dimensionless form as follows:

$$
\nabla^{*} \bullet \vec{U}^{*}=0
$$

The following relations can be obtained for the dimensionless velocity components and the dimensionless pressure, respectively, by inspection analysis of Eqs. (2) and (5), as follows:

$$
\begin{aligned}
\vec{U}^{*} & =f_{1}\left(\vec{x}^{*}, t^{*}, \operatorname{Re}, F r\right), \\
p^{*} & =f_{2}\left(\vec{x}^{*}, t^{*}, \operatorname{Re}, F r\right),
\end{aligned}
$$

where $\vec{x}^{*}$ is a dimensionless location vector.

For stationary flow with a periodic character the velocity time dependence can be eliminated by substituting the velocity and pressure by time-averaged properties. For highly turbulent flow in a baffled vessel, the viscous and gravitational forces can be neglected and finally the time-averaged dimensionless velocity components and the pressure are independent of the impeller Reynolds and the Froude numbers, and depend on location only:

$$
\begin{aligned}
& \bar{U}_{i}^{*}=f_{1}\left(\vec{x}^{*}\right), \\
& p^{*}=f_{2}\left(\vec{x}^{*}\right) .
\end{aligned}
$$

Reynolds decomposition of instantaneous velocity components has been applied for the velocity profiles studied in this work.

\subsection{Mean and fluctuation velocity}

Using PIV, the instantaneous velocity data set $U_{i}\left(t_{j}\right)$ in the $\mathrm{i}^{\text {th }}$ direction for $j=1,2, \ldots N_{R}$ at observation times $t_{j}$ with equidistant time step $\Delta t_{S}$ (i.e. $\Delta t_{S}=t_{j+1}-t_{j}$ ) was obtained in a given location. Assuming the ergodic hypothesis the time-averaged mean velocity $\bar{U}_{i}$ was determined as the average value of velocity data set $U_{i}$ $\left(t_{j}\right)$ :

$$
\overline{U_{i}}=\frac{1}{N_{R}} \cdot \sum_{j} U\left(t_{j}\right) \text { for } j=1,2, \ldots, N_{R},
$$

where $\bar{U}_{i}$ is mean velocity in the $\mathrm{i}^{\text {th }}$ direction, $U_{i}\left(t_{j}\right)$ is instantaneous velocity in the $i^{\text {th }}$ direction at the observation time $t_{j}$, and $N_{R}$ is the number of data items in the velocity data set.

Consequently, the fluctuation velocity in the $\mathrm{i}^{\text {th }}$ direction $u_{i}\left(t_{j}\right)$ at observation time $t_{j}$ is obtained by decomposition of the instantaneous velocity:

$$
u_{i}\left(t_{j}\right)=U_{i}\left(t_{j}\right)-\bar{U}_{i} \text { for } j=1,2, \ldots, N_{R}
$$

where $u_{i}\left(t_{j}\right)$ is the fluctuation velocity in the $\mathrm{i}^{\text {th }}$ direction at observation time $\mathrm{t}_{\mathrm{i}}, \bar{U}_{i}$ is mean velocity in the $\mathrm{i}^{\text {th }}$ direction, $U_{i}\left(t_{i}\right)$ is instantaneous velocity in the $i^{\text {th }}$ direction at the observation time $t_{i}$.

The root mean squared fluctuation velocity is determined as follows:

$$
\bar{u}_{i}=\left(\frac{1}{N_{R}} \cdot \sum_{i} u_{i}^{2}\left(t_{j}\right)\right)^{1 / 2} \text { for } j=1,2, \ldots, \mathrm{N}_{\mathrm{R}},
$$

where $\bar{u}_{i}$ is the root mean squared fluctuation velocity, and $u\left(t_{i}\right)$ is the fluctuation velocity at observation time $t_{i}$.

\section{Experimental}

The hydrodynamics and the flow field were investigated in an agitated vessel using Time Resolved Particle Image Velocimetry (TR PIV). The experiments were carried out in a fully baffled cylindrical flat bottom vessel 400 $\mathrm{mm}$ in the inner diameter. The tank was agitated by a Rushton turbine $133 \mathrm{~mm}$ in diameter, i.e. the dimensionless impeller diameter $D / T$ was $1 / 3$. The dimensionless impeller clearance $C / D$ taken from the lower impeller edge was 0.75 . The tank was filled with degassed liquid, and the liquid height was $400 \mathrm{~mm}$, i.e. the dimensionless liquid height $H / T$ was 1 . 
Table 1. Operational parameters.

\begin{tabular}{|c|c|c|c|c|c|}
\hline Run \# & liquid & $\begin{array}{c}\mathrm{N} \\
(\mathrm{rpm})\end{array}$ & $\begin{array}{c}v \\
\left(\mathrm{~m}^{2} / \mathrm{s}\right)\end{array}$ & $\begin{array}{c}\text { Re } \\
(-)\end{array}$ & $\begin{array}{c}\text { Record time } \mathrm{T}_{\mathrm{R}} \\
(\mathrm{s})\end{array}$ \\
\hline w-N300 & water & 300 & $9.35 \times 10^{-7}$ & 94641 & 24.8 \\
w-N600 & water & 600 & $9.35 \times 10^{-7}$ & 189282 & 24.8 \\
g28-N600 & $28 \%$ glycol & 600 & $2 \times 10^{-6}$ & 88445 & 24.8 \\
g28-N750 & $28 \%$ glycol & 750 & $2 \times 10^{-6}$ & 110556 & 24.8 \\
g43-N600 & $43 \%$ glycol & 600 & $3 \times 10^{-6}$ & 58963 & 24.8 \\
g43-N750 & $43 \%$ glycol & 750 & $3 \times 10^{-6}$ & 73704 & 24.8 \\
g43-N850 & $43 \%$ glycol & 850 & $3 \times 10^{-6}$ & 83531 & 24.8 \\
\hline
\end{tabular}

The dimensionless baffle width $B / T$ was $1 / 10$. To prevent air suction the vessel was covered by a lid.

Three liquids of different viscosities were used as the agitated liquid: i) distilled water $\left(v=9.35 \times 10^{-7} \mathrm{~m}^{2} / \mathrm{s}\right)$, ii) a $28 \%$ vol. aqueous solution of glycol $\left(v=2 \times 10^{-6} \mathrm{~m}^{2} / \mathrm{s}\right)$, and iii) a $43 \%$ vol. aqueous solution of glycol $\left(v=3 \times 10^{-}\right.$ $\left.{ }^{6} \mathrm{~m}^{2} / \mathrm{s}\right)$. The velocity fields were measured at an impeller rotation speed in the range from $300 \mathrm{rpm}$ to $850 \mathrm{rpm}$, which covers the impeller Reynolds number range from 50000 to 189000 . This Re range secures the fullydeveloped turbulent flow. The operational conditions are summarized in Table 1.
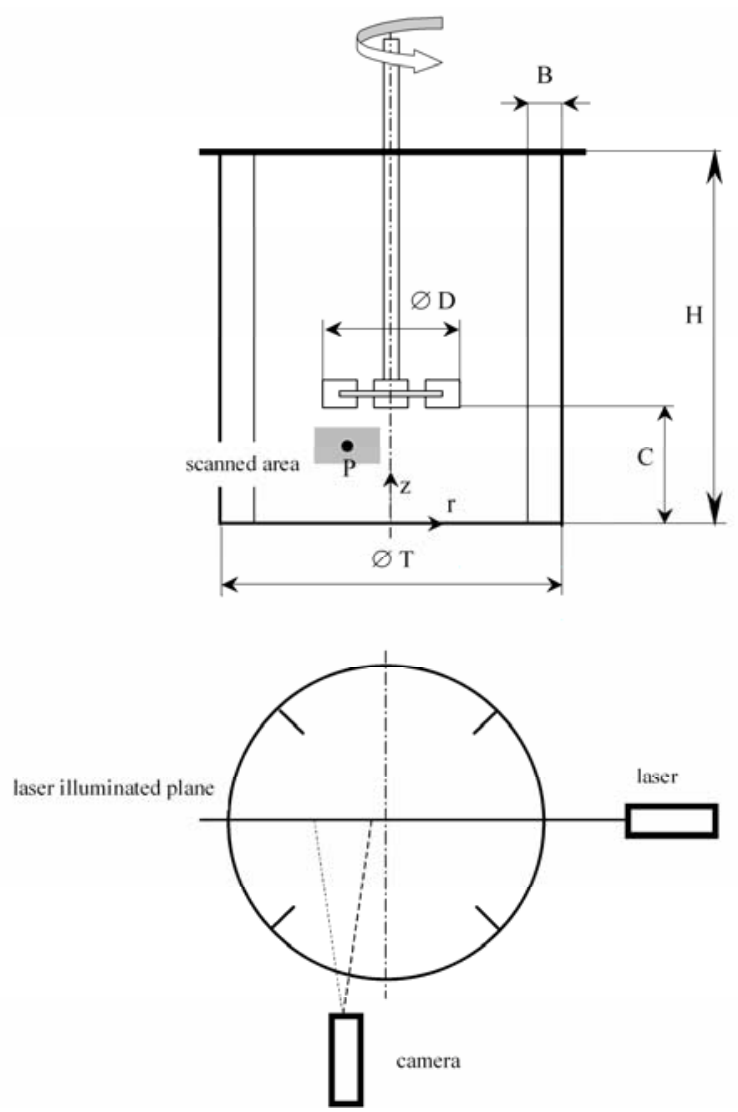

Fig. 1. Scheme of the experimental apparatus and the investigated area.

The time-resolved LITRON LDY 302 2D-PIV system (Dantec Dynamics (Denmark)) consists of a Neodyme-YLF laser (light wave length $532 \mathrm{~nm}$, impulse energy 2x15 mJ), a SpeedSence 611 high speed PIVregime camera (working on frequency $1 \mathrm{kHz}$ with resolution 1280 x 800 pixels) with a Nikon Macro 200 optical lens system equipped with an optical filter of wave length $570 \mathrm{~nm}$. Rhodamine B fluorescent particles $11.95 \pm 0.25 \mu \mathrm{m}$ in mean diameter were used as seeding particles. The fluorescent particles lit by $532 \mathrm{~nm}$ light emit $570 \mathrm{~nm}$ light. In this way, non-seeding particles such as impurities and bubbles are separated, and are not recorded. The operating frame rate was $1 \mathrm{kHz}(1000$ vector fields per second), i.e. the sampling time $\Delta t_{s}$ was 1 $\mathrm{ms}$. The measured vertical plane was located in the center of the vessel and in the middle of the baffles. The plane was illuminated by a laser sheet. The investigated area was $43 \times 27 \mathrm{~mm}$, and the PIV spatial resolution $\Delta=$ $0.74 \mathrm{~mm}$ was maintained the same during the experiment.

The position of middle point $\mathrm{P}$ of the investigated area corresponds to dimensionless radius $2 r / T=0.224$ and dimensionless height $z / T=0.138$. The scheme of the experimental apparatus and the investigated area is depicted in Fig. 1. The camera was positioned orthogonally to the laser sheet. The investigated area corresponds to region $\mathrm{F}$ according to the classification given by Forrt et al. [4]. The method of ensemble averaged velocity field can be used due to the axisymmetric character of the flow in this region.

\section{Experimental data evaluation}

According to the inspection analysis, the dimensionless velocities normalized by the product of impeller speed $N$ and impeller diameter $D$ should be independent of the impeller Reynolds number.

The effect of impeller Reynolds number on dimensionless velocities was tested by hypothesis testing ([5]). The statistical method of hypothesis testing can estimate whether the differences between the predicted parameter values (e.g. according to some proposed theory) and then the parameter values evaluated from the measured data are negligible. In this case, we assumed dependence of the tested parameter on the impeller Reynolds number, described by the simple power law correlation parameter $=B \cdot R^{\beta}$, and the difference between predicted exponent $\beta_{\text {pred }}$ and evaluated exponent $\beta_{\text {calc }}$ was tested. The hypothesis test characteristics are given as $t=\left(\beta_{\text {calc }}-\beta_{\text {pred }}\right) / s_{\beta}$ where $s_{\beta}$ is the standard error of parameter $\beta_{\text {calc }}$. 
Table 2. Dimensionless velocities - effect of the impeller Reynolds number

\begin{tabular}{|c|c|c|}
\hline & \multicolumn{2}{|c|}{$\begin{array}{c}\text { Hypothesis: parameter }=\mathrm{B} .(\mathrm{Re})^{0} \\
\text { percentage } / \mathrm{t} \text {-characteristics }|\mathrm{t}|\end{array}$} \\
\hline Parameter & acceptable & not acceptable \\
\hline $\bar{U}_{r} /(N D)(-)$ & $97.9 \% / 0.62$ & $2.1 \% / 3.1$ \\
\hline $\bar{U}_{a x} /(N D)(-)$ & $87.2 \% / 1.3$ & $12.8 \% / 3.4$ \\
\hline $\bar{u}_{r} /(N D)(-)$ & $92 \% / 0.62$ & $8 \% / 3.4$ \\
\hline $\bar{u}_{a x} /(N D)$ & $98.7 \% / 1.0$ & $1.3 \% / 2.8$ \\
\hline T.I. $_{\mathrm{ax}}(-)$ & $86.1 \% / 1.3$ & $13.9 \% / 3.1$ \\
\hline
\end{tabular}

If the calculated $|t|$ value is less than the critical value of the t-distribution for $(m-2)$ degrees of freedom and significance level $\alpha$, the difference between $\beta_{\text {calc }}$ and $\beta_{\text {pred }}$ is statistically negligible (statisticians state: "the hypothesis cannot be rejected"). In our case, the independence of dimensionless velocities of the impeller Reynolds number was tested as the hypothesis, i.e. parameter $=B .(R e)^{0}=$ const., i.e. $\beta_{\text {pred }}=0$. The $\mathrm{t}-$ distribution coefficient $t_{(m-2), \alpha}$ for seven impeller Reynolds numbers and significance level $\alpha=0.05$ is 2.5706. The hypothesis testing was done for each point in the investigated area. The hypothesis test results are presented for investigated area in Table 2 by the percentage of points in which the above-formulated hypothesis parameter $=$ const . is satisfied and by the percentage of points in which the hypothesis parameter
$=$ const . can not be accepted. For illustration, the average values of calculated $|t|$ value are presented here also.

The dimensionless radial mean velocities were found to be close to zero, in the range from 0.008 to 0.074 . These findings correspond to characteristics of the given zone, according to Fořt et al. [4]. This region contains predominantly ascending flow along the vessel axis towards the impeller. The dimensionless axial mean velocity was found to be in the range from 0.317 to 0.511 . These values are higher than the dimensionless values for radial mean velocity as expected for this region. The tested hypothesis can be accepted in the majority of profile points of the investigated area.

The dimensionless radial r.m.s. fluctuation velocities were found to be in the range from 0.189 to 0.323 . The tested hypothesis can be accepted in the majority of profile points, as is signalized by the very low calculated $|t|$ values. The dimensionless axial r.m.s. fluctuation velocities were found to be in the range from 0.153 to 0.295 . The tested hypothesis can be accepted in the majority of profile points as is again signalized by the low calculated $|t|$ values.

On the basis of the results of this hypothesis test, we assume that all dimensionless velocities can be statistically taken as constant and independent of the impeller Reynolds number. The spatial distributions of dimensionless velocities for seven operational conditions were averaged and are presented in Figures $2-5$. For illustration, the radial profiles of velocity components are presented in Figures 6 - 9 for selected horizontal positions $z^{*}=0.120,0.135$ and 0.150 . The profiles obtained are in accordance with velocity profiles typical for region $\mathrm{F}$ as reported by Fořt et al. [4].

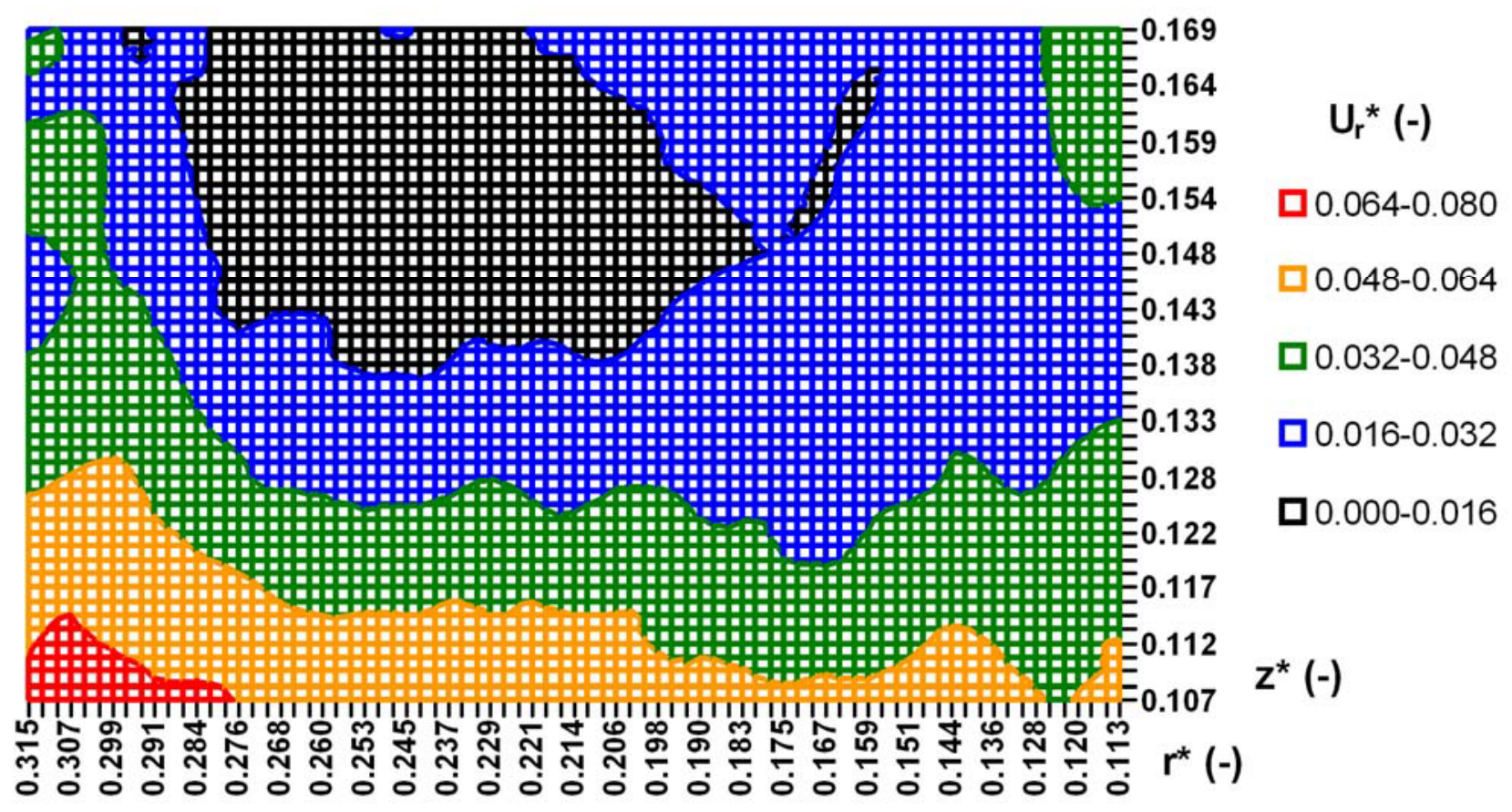

Fig. 2. Dimensionless radial mean velocity distribution $U_{r}{ }^{*}=\bar{U}_{r} /(N D)=\mathrm{f}\left(r^{*}, z^{*}\right)$. 


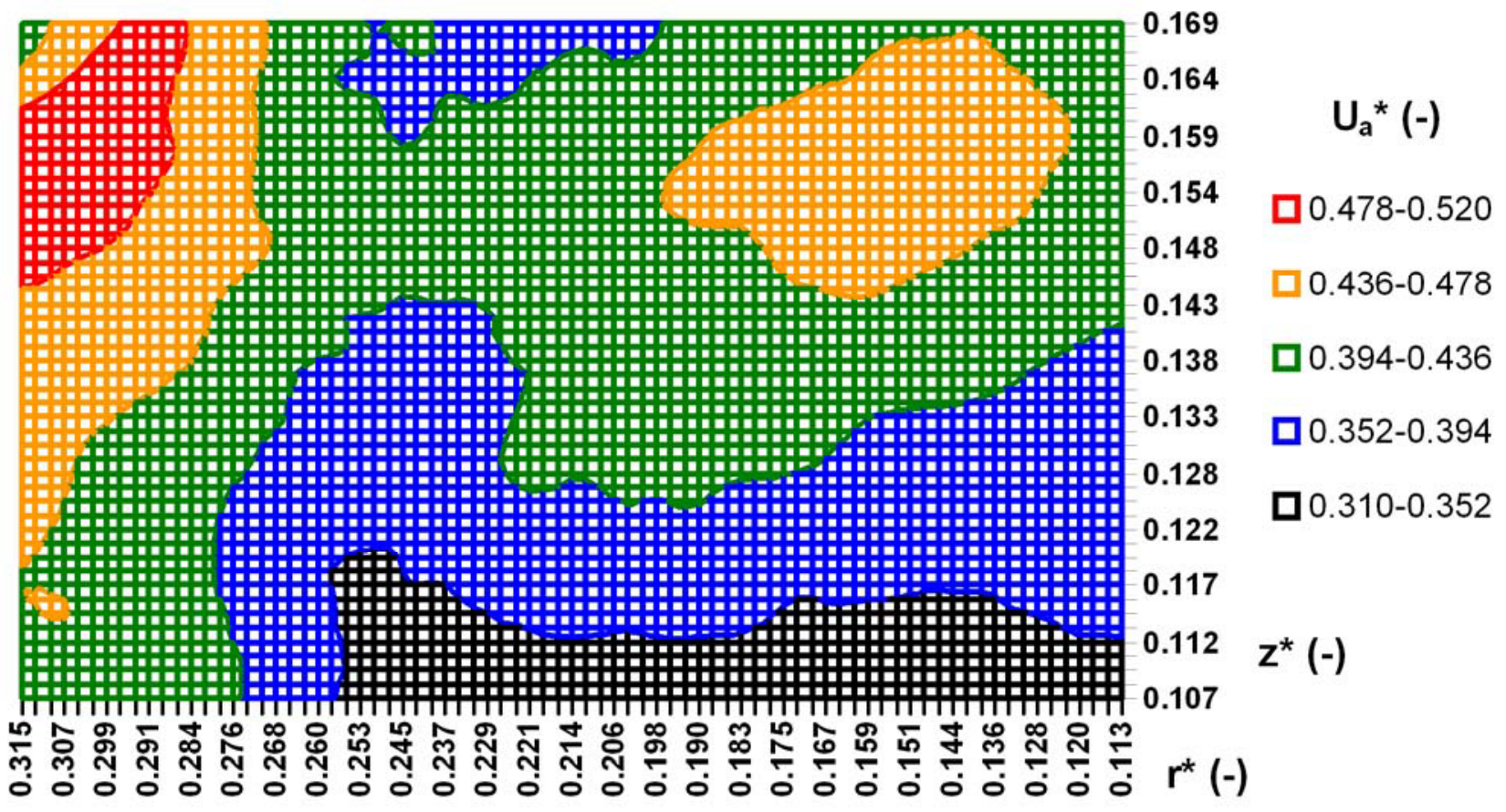

Fig. 3. Dimensionless axial mean velocity distribution $U_{a x}{ }^{*}=\bar{U}_{a x} /(N D)=\mathrm{f}\left(r^{*}, z^{*}\right)$.

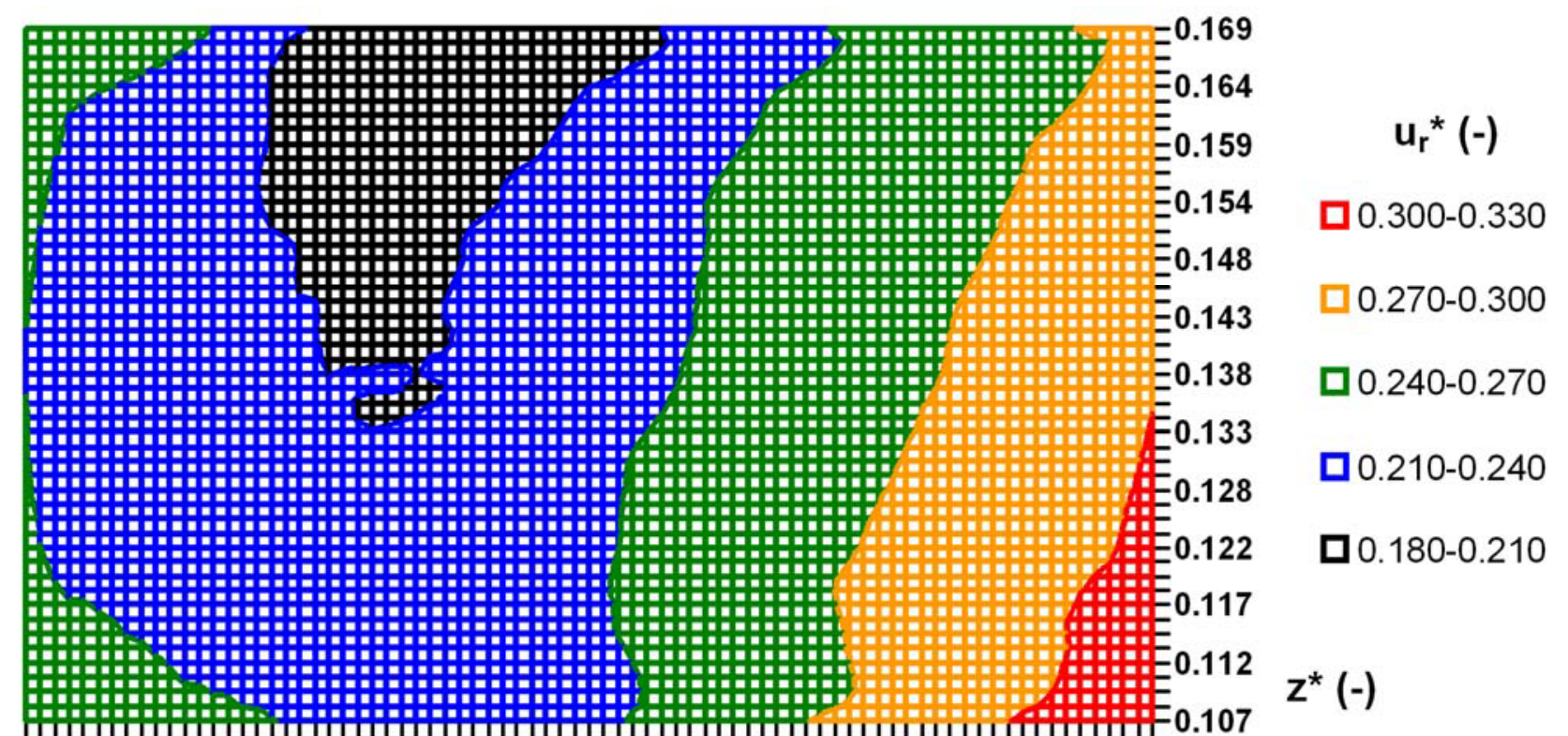

ผ

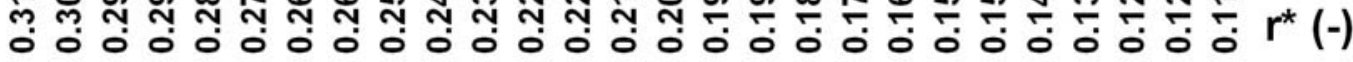

Fig. 4. Dimensionless radial fluctuation velocity distribution $u_{r}{ }^{*}=\bar{u}_{r} /(N D)=\mathrm{f}\left(r^{*}, z^{*}\right)$. 


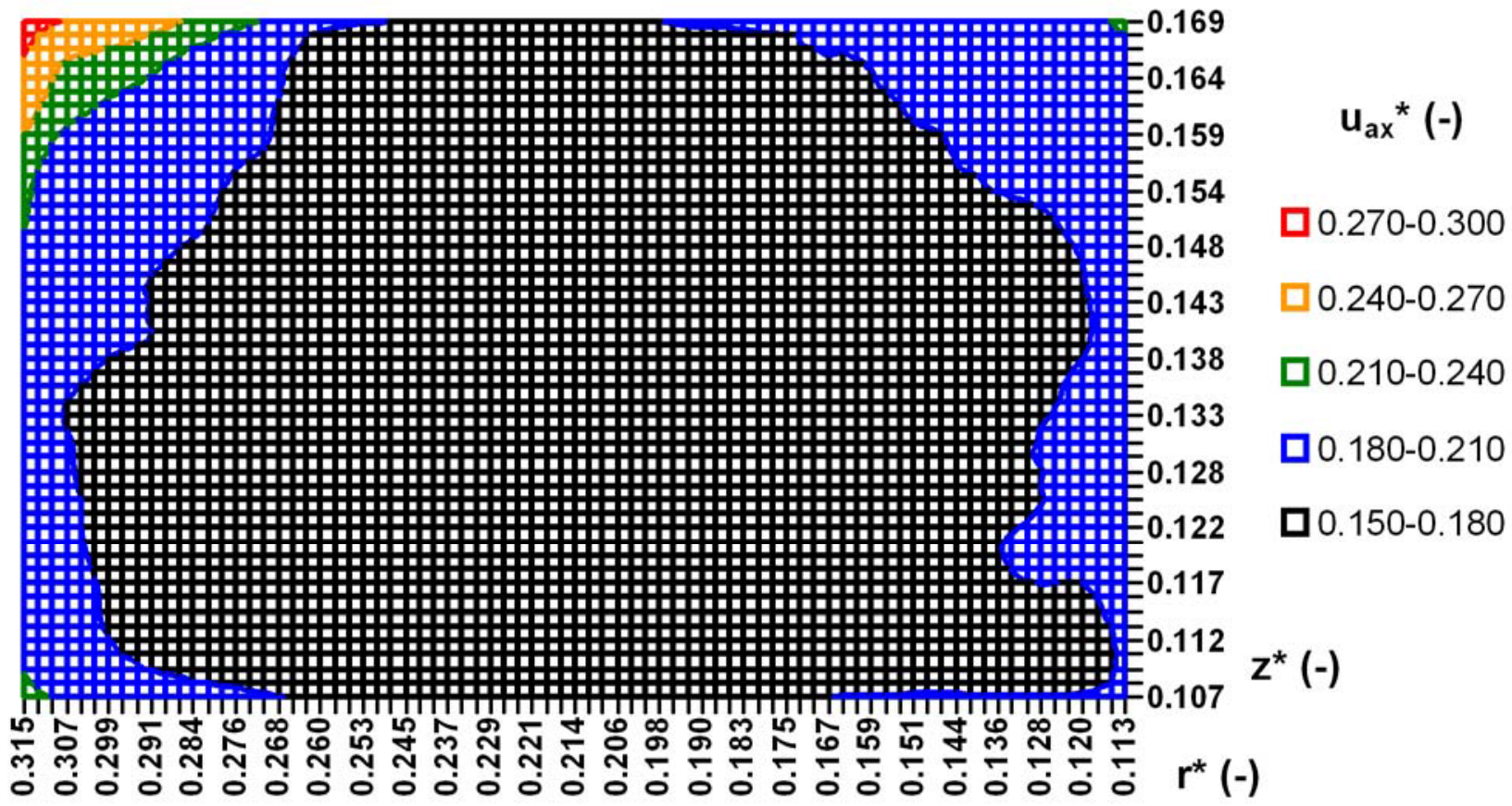

Fig. 5. Dimensionless axial fluctuation velocity distribution $u_{a x}{ }^{*}=\bar{u}_{a x} /(N D)=\mathrm{f}\left(r^{*}, z^{*}\right)$.
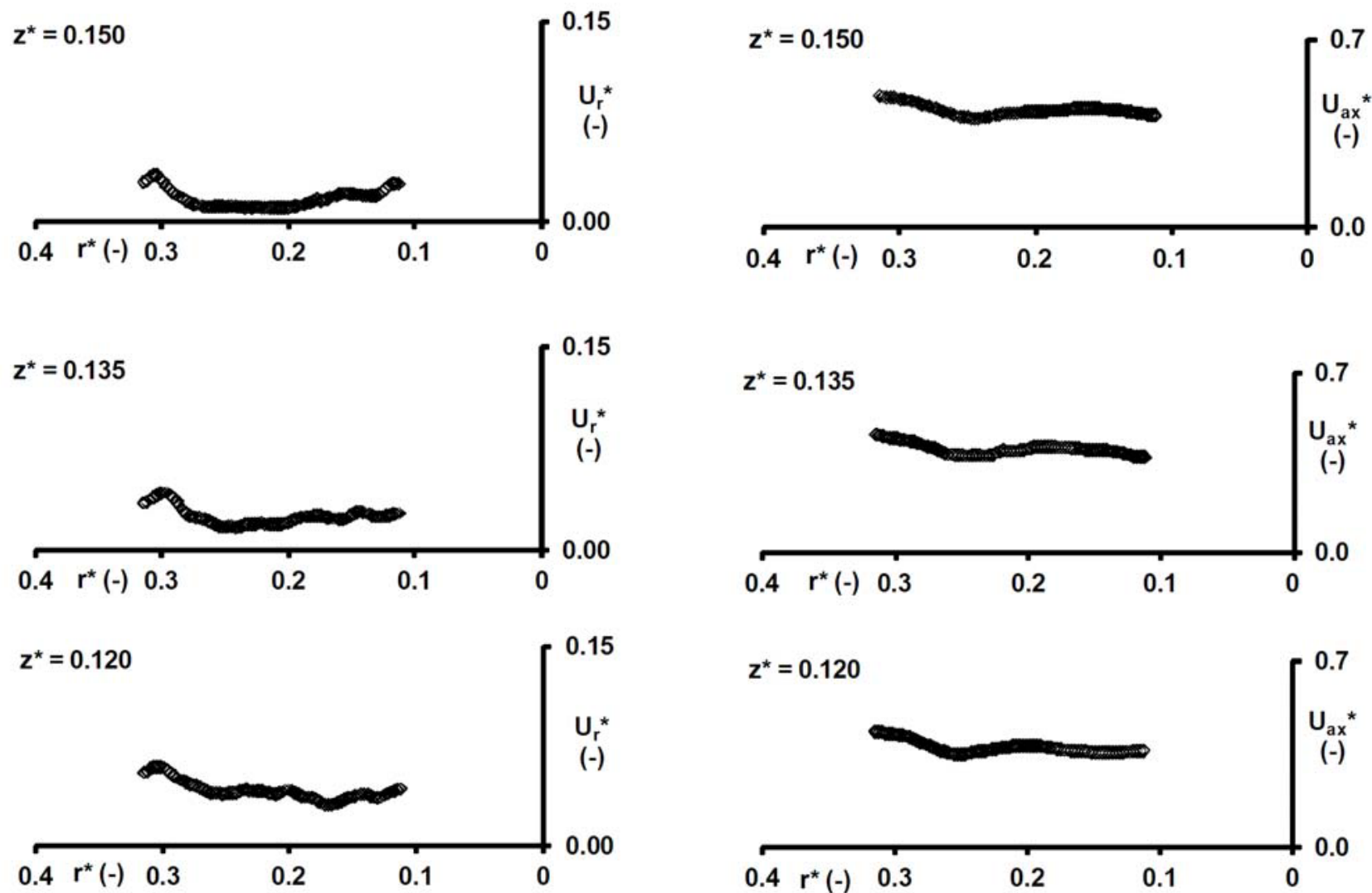

Fig. 6. Dimensionless radial mean velocity profiles $\bar{U}_{r} /(N D)=\mathrm{f}\left(r^{*}\right)$.

Fig. 7. Dimensionless axial mean velocity profile $\bar{U}_{a x} /(N D)=\mathrm{f}\left(r^{*}\right)$. 

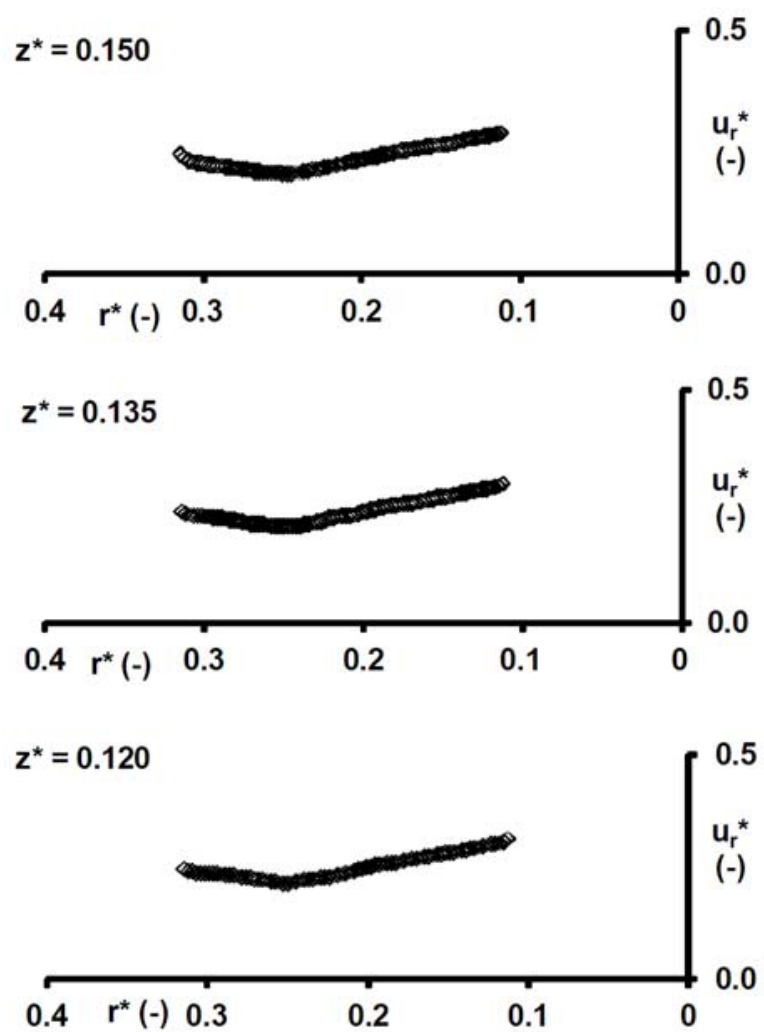

Fig. 8. Dimensionless radial fluctuation velocity profile

$$
\bar{u}_{r} /(N D)=\mathrm{f}\left(r^{*}\right)
$$
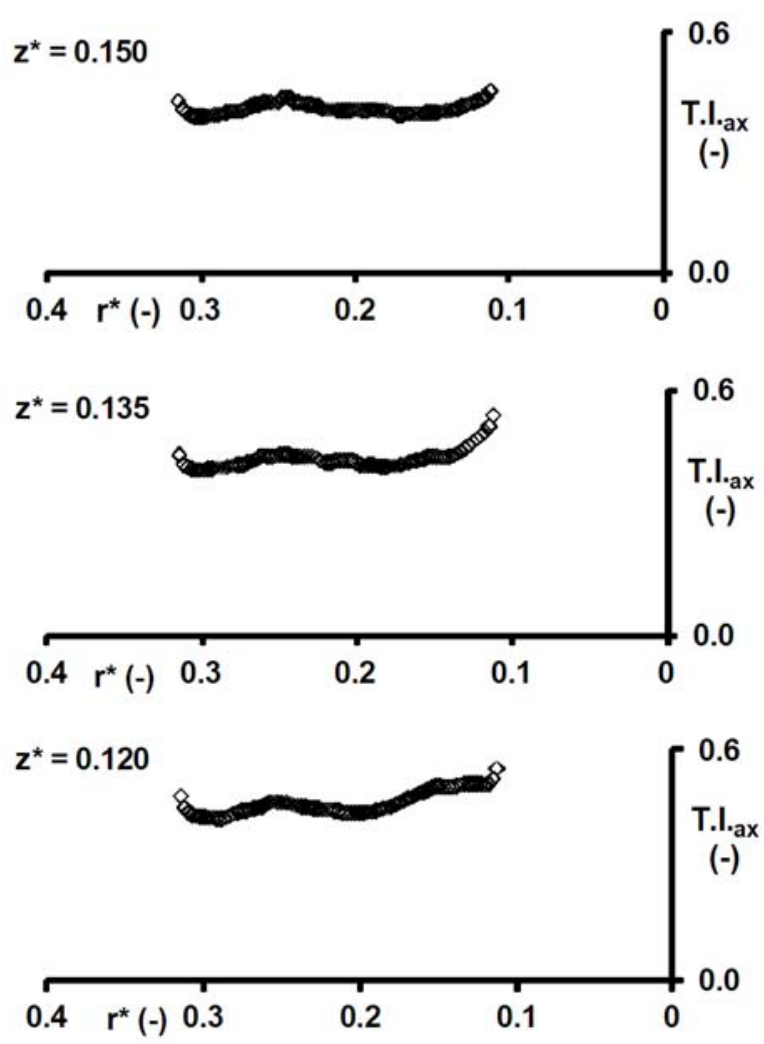

Fig. 10. Axial turbulence intensity profile T.I. $a x=\mathrm{f}\left(r^{*}\right)$.
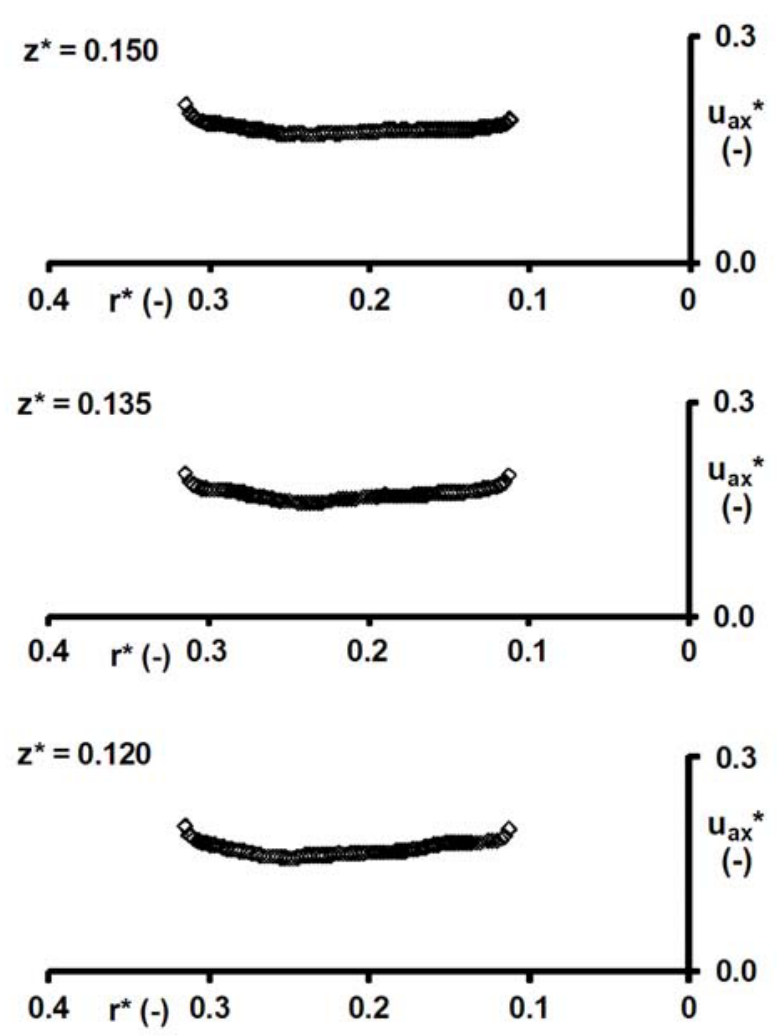

Fig. 9. Dimensionless axial fluctuation velocity profile

$$
\bar{u}_{a x} /(N D)=\mathrm{f}\left(r^{*}\right)
$$

\section{Intensity of turbulence}

The axial turbulence intensity was calculated for each point in the investigated area as follows:

$$
T . I \cdot a x=\frac{\bar{u}_{a x}}{\bar{U}_{a x}}
$$

where $\bar{u}_{a x}$ is axial r.m.s. fluctuation velocity, $\bar{U}_{a x}$ is axial mean velocity. For dimensionless velocities independent of the impeller Reynolds number, the turbulence intensity should also be independent of this quantity. The independence of dimensionless velocities from the impeller Reynolds number was again tested by hypothesis testing. The $\mathrm{t}$-distribution coefficient $\mathrm{t}_{(\mathrm{m}-2), \alpha}$ for seven impeller Reynolds numbers and significance level $\alpha=0.05$ is 2.5706 . Hypothesis testing was done for each point in the investigated area. The hypothesis test results are presented in Table 2, as well. 


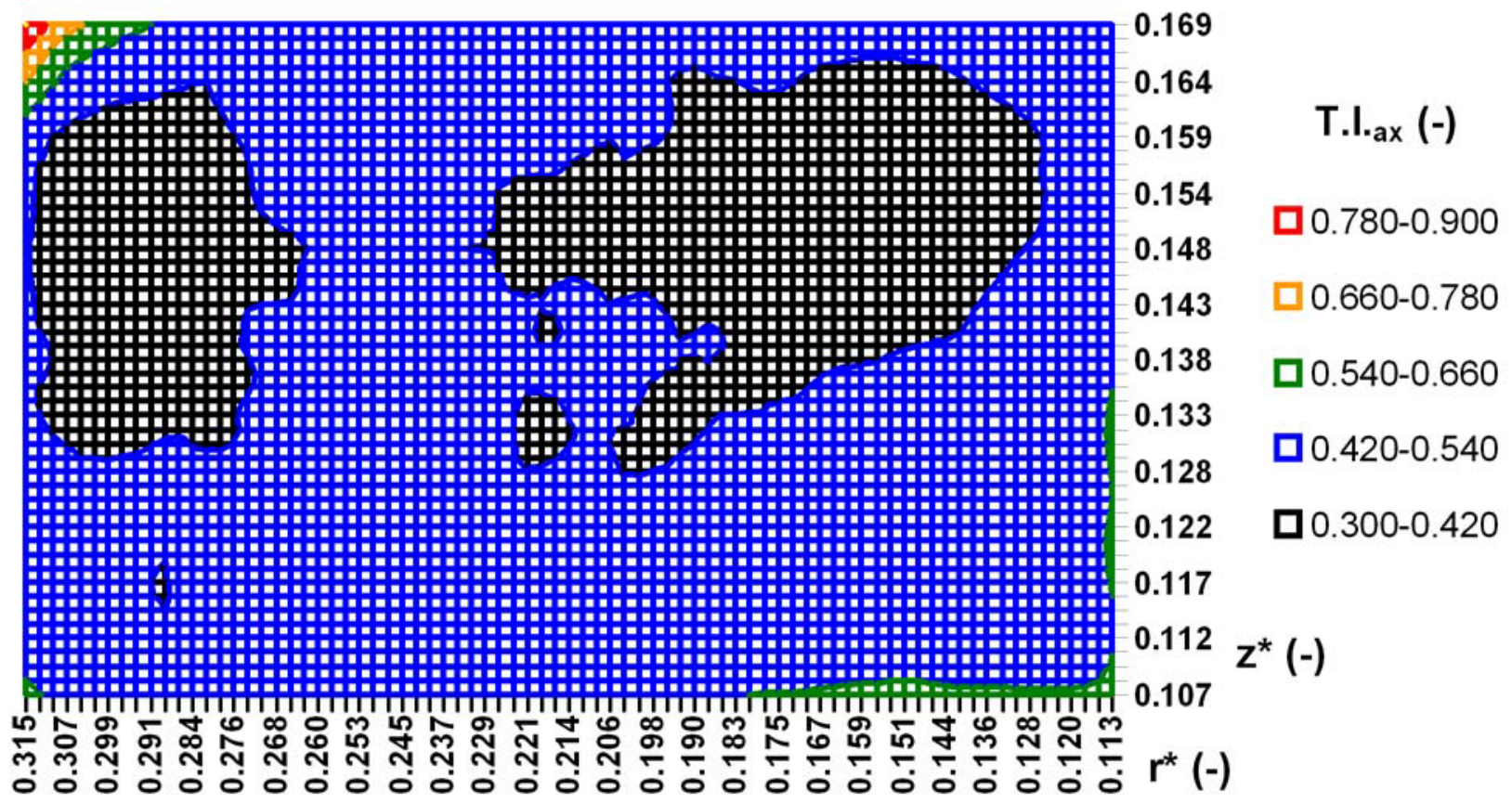

Fig. 11. Axial turbulence intensity distribution T.I. $a x=\mathrm{f}\left(r^{*}, z^{*}\right)$.

The tested hypothesis can be accepted in the majority of profile points On the basis of these hypothesis test results, we assume that the axial turbulence intensity can be statistically taken as constant and independent of the impeller Reynolds number, as expected. As shown, the calculated values are in the majority of points in the range from 0.388 to 0.540 . These values correspond to high turbulence intensity. As expected, the highest turbulence intensity was found close to the impeller axis in the ascending flow core. The radial profiles of axial turbulence intensity are presented in Figure 10 for selected horizontal positions $z^{*}=0.120,0.135$ and 0.150 . The spatial distribution of quantity T.I.ax is shown in Figure 11.

\section{Experimental data evaluation}

The following results have been obtained in this study:

The hydrodynamics and flow field were measured in a vessel $400 \mathrm{~mm}$ in the inner diameter agitated by a Rushton turbine using the 2-D Time Resolved Particle Image Velocimetry (2-D TR PIV). The velocity fields were measured in the zone in upward flow to the impeller for impeller rotation speeds from $300 \mathrm{rpm}$ to $850 \mathrm{rpm}$ and three liquids of different viscosities, corresponding to the impeller Reynolds number in the range $50000<\mathrm{Re}<189000$.

The dimensionless radial mean velocities were found to be close to zero. These findings correspond to the characteristics of the given zone according to Fořt et al. [4]. This region contains predominantly ascending flow along the vessel axis towards the impeller.

In accordance with the theory of mixing, the dimensionless mean and fluctuation velocities in measured directions were found to be constant and independent of the impeller Reynolds number. On the basis of the test results the spatial distributions of dimensionless velocities were calculated.

The axial turbulence intensity was calculated and was found to be in the majority of points in the range from 0.388 to 0.540 , which corresponds to high level of turbulence intensity. As expected, the highest turbulence intensity was found close to the impeller axis in the ascending flow core. It was found that the axial turbulence intensity can be statistically taken as constant and independent of the impeller Reynolds number.

This research has been supported by Grant Agency of the Czech Republic project No. 16-20175S and by Ministry of Education, Youth and Sports of the Czech Republic project No. LO1201 (National Programme for Sustainability I) and RVO:67985874.

\section{Symbols}

B baffle width, $\mathrm{m}$

C impeller clearance, $m$

$\mathrm{D}$ impeller diameter, $\mathrm{m}$

$\mathrm{H}$ liquid height, $\mathrm{m}$

$\mathrm{m}$ number of experimental points, -

$\mathrm{N}$ impeller rotational speed, $1 / \mathrm{s}$

$\mathrm{N}_{R}$ number of data in velocity data set, -

$\mathrm{r}$ radius (radial coordinate), $\mathrm{m}$

$r^{*} \quad$ dimensionless radius; $r^{*}=2 r / T$, -

$\mathrm{Re}$ impeller Reynolds number; $\mathrm{Re}=\mathrm{N} . \mathrm{D}^{2} / \mathrm{v}$, -

$\mathrm{t}$ time, $\mathrm{s}$

$t_{i}$ observation time, $s$

$t_{R} \quad$ record time, $s$

$t_{(m-2), a}=0.05 \quad t$-distribution for $(m-2)$ degrees of freedom and significance level $\alpha$, -

$\mathrm{T}$ tank diameter, $\mathrm{m}$

T.I. turbulence intensity, -

$\mathrm{u}_{\mathrm{i}} \quad$ fluctuation velocity in $\mathrm{i}^{\text {th }}$ direction, $\mathrm{m} / \mathrm{s}$ 
$\bar{u}_{i} \quad$ root mean squared fluctuation velocity in $\mathrm{i}^{\text {th }}$ direction, $\mathrm{m} / \mathrm{s}$

$\mathrm{U}_{\mathrm{i}} \quad$ instantaneous velocity in $\mathrm{i}^{\text {th }}$ direction, $\mathrm{m} / \mathrm{s}$

$\bar{U}_{i}$ mean velocity in $\mathrm{i}^{\text {th }}$ direction, $\mathrm{m} / \mathrm{s}$

$\mathrm{z} \quad$ actual height (axial coordinate), $\mathrm{m}$

$z^{*} \quad$ dimensionless height; $z^{*}=z / T$, -

\section{References}

1. B. Kysela, J. Konfršt, I. Fořt, M. Kotek, Z. Chára, Chem. and process Eng., 35, 137-147 (2014)

2. R. Šulc, V. Pešava, P. Ditl, Acta Polytechnica, 54, 430-438 (2014)

3. V. Novák, F. Rieger, K. Vavro, Hydraulické pochody $v$ chemickém a potravinářském průmyslu (SNTL, Prague, 1989)

4. I. Fořt, A. Obeid, V. Březina, Coll. Czechoslov. Chem. Comm., 47, 226-239 (1982)

5. B.L. Bowerman, R.T.O'Connell, Applied statistics: improving business processes (Richard D. Irwin, USA, 1997) 